\title{
BMJ Open Choosing appropriate tools and referral criteria for vision screening of children aged 4-5 years in Canada: a quantitative analysis
}

\author{
Mayu Nishimura, ${ }^{\oplus 1,2}$ Agnes Wong, ${ }^{1,3,4}$ Ashley Cohen, ${ }^{5}$ Kevin Thorpe, ${ }^{4,5}$ \\ Daphne Maurer ${ }^{2,4}$
}

To cite: Nishimura M, Wong A, Cohen A, et al. Choosing appropriate tools and referral criteria for vision screening of children aged $4-5$ years in Canada: a quantitative analysis. BMJ Open 2019;9:e032138. doi:10.1136/ bmjopen-2019-032138

- Prepublication history and additional material for this paper are available online. To view these files, please visit the journal online ().

Received 05 June 2019 Revised 03 September 2019 Accepted 05 September 2019

Check for updates

(c) Author(s) (or their employer(s)) 2019. Re-use permitted under CC BY-NC. No commercial re-use. See rights and permissions. Published by BMJ.

${ }^{1}$ Department of Ophthalmology and Vision Sciences, The Hospital for Sick Children, Toronto, Ontario, Canada ${ }^{2}$ Department of Psychology, Neuroscience \& Behaviour, McMaster University, Hamilton, Ontario, Canada

${ }^{3}$ Ophthalmology and Vision Sciences, University of Toronto, Toronto, Ontario, Canada ${ }^{4}$ Dalla Lana School of Public Health, University of Toronto, Toronto, Ontario, Canada ${ }^{5}$ Applied Health Research Centre, Li Ka Shing Knowledge Institute, Toronto, Ontario, Canada

Correspondence to Dr Mayu Nishimura; mayu.nishimura@sickkids.ca

\section{ABSTRACT}

Objectives To assess the diagnostic accuracy of five vision screening tools used in a school setting using sensitivity, specificity, positive predictive value (PPV) and negative predictive value (NPV).

Design We compared the results of the five best evidence-based screening tools available in 2014 to the results of a comprehensive eye exam with cycloplegic refraction by a licenced optometrist. Screening included Cambridge Crowded Acuity Cards, Plusoptix S12 and Spot photoscreeners, Preschool Randot Stereoacuity Test and the Pediatric Vision Scanner (PVS). Referral criteria followed AAPOS (2013) guidelines and published norms. Setting A large school in Toronto, Canada, with 25 split classrooms of junior kindergarten (JK: 4 year olds) and senior kindergarten (SK: 5 year olds) children.

Participants Over 2 years, 1132 eligible children were enrolled at the school. After obtaining parental consent, 832 children were screened. Subsequently, 709 children had complete screening and optometry exam data.

Main outcome measures The presence/absence of a visual problem based on optometrist's assessment: amblyopia, amblyopia risk factors (reduced stereoacuity, strabismus and clinically significant refractive errors) and any other ocular problem (eg, nystagmus).

Results Overall, $26.5 \%$ of the screened children had a visual problem, including $5.9 \%$ with amblyopia. Using all five tools, screening sensitivity $=84 \%(95 \% \mathrm{Cl} 78$ to 89$)$, specificity $=49 \%(95 \% \mathrm{Cl} 44$ to 53), PPV $=37 \%(95 \% \mathrm{Cl}$ 33 to 42$)$, and NPV $=90 \%(95 \% \mathrm{Cl} 86$ to 93$)$. The odds of having a correct screening result in SK (mean age $=68.2$ months) was 1.5 times those in $\mathrm{JK}$ (mean age $=55.6$ months; $95 \% \mathrm{Cl} 1.1$ to 2.1 ), with sensitivity improved to $89 \%$ (95\% Cl 80 to 96$)$ and specificity improved to $57 \%$ (95\% Cl 50 to 64) among SK children.

Conclusions A school-based screening programme correctly identified $84 \%$ of those kindergarten children who were found to have a visual problem by a cyclopleged optometry exam. Additional analyses revealed how accuracy varies with different combinations of screening tools and referral criteria.

\section{BACKGROUND}

The early detection of amblyopia is an important public health issue because, if left
Strengths and limitations of this study

- Over 700 typically developing children underwent screening and cyclopleged optometry exams by a licenced optometrist.

- Comparative advantages (sensitivity, specificity, positive predictive value and negative predictive value) calculated for five screening tools and all possible combinations.

- Diagnostic accuracy calculated for different referral criteria for each screening tool.

Results compared for children aged 4-5 years.

untreated past about age 7 years, it leads to a lifetime of reduced vision in a structurally normal eye secondary to abnormal visual experience early in life. ${ }^{1-3}$ Amblyopia is the most common cause of blindness in one eye and increases the risk of losing the other 'good' eye and concomitant risk of job loss. ${ }^{4-7}$ It also leads to impaired binocular vision and reading $^{89}$ : by $8-12$ years of age, children with amblyopia read more slowly than those with normal vision. ${ }^{1011}$ The prevalence of amblyopia is estimated to be $3 \%-5 \%$ in children aged 3-6 years. ${ }^{12-16}$ Risk factors for amblyopia include clinically significant, untreated refractive errors, which occur in roughly $10 \%$ of children aged 3-6 years. ${ }^{17-22}$ Timely prescription of glasses can be all that is necessary to prevent amblyopia and the learning difficulties. $^{23-29}$ For example, in 4-year-old children with hyperopia (far-sightedness) who wore glasses for as little as 6 weeks, IQ scores improved to a level comparable with the control group, with a significant improvement in visual motor subtest scores. ${ }^{30}$

Early visual screening is associated with a decrease in the prevalence of amblyopia and improved acuity. ${ }^{31-33}$ The US Preventive Services Task Force systematically reviewed the evidence on vision screening in 2011 
and again in 2017 and recommended that children age 3-5 years be screened for vision problems. ${ }^{34-36}$ However, systematic reviews of the literature question the effectiveness of vision screening programmes. ${ }^{37}{ }^{38}$ The seminal study by the Vision In Preschoolers (VIP) Group in 2004 tested 11 preschool vision screening tests administered by optometrists/ophthalmologists and compared their results with those from standardised comprehensive eye examinations. ${ }^{19}$ With specificity set at $90 \%$ (in an attempt to prevent false referrals), sensitivity ranged from $16 \%$ (cover-uncover test) to 64\% (non-cyloplegic retinosocopy). A follow-up study found that lay screeners were just as effective as nurse screeners in administering the screening tests, with the four best tests being non-cyloplegic retinoscopy, Retinomax Photoscreener, SureSight Vision Screener and crowded Linear Lea Symbols. ${ }^{39}$ However, since the publication of these studies, newer photoscreeners have become available (Plusoptix; Spot by Welch Allyn) that have high agreement with cyclopleged eye examinations. ${ }^{40}$ In addition, a new electronic hand-held device, the Pediatric Vision Scanner (PVS), has been developed that detects strabismus and amblyopia by measuring binocular fixation. ${ }^{41}$ It is unclear how accurately these newer screening tools can detect visual problems in a non-clinical population of children aged 3-6 years, when used in combination with traditional tests of visual acuity and stereoacuity.

The primary purpose of the present study was to conduct an updated assessment of paediatric vision screening tools in a normative sample of children. Our goal was to determine the sensitivity and specificity of the five best evidence-based screening tools available at the start of the study in 2014, by evaluating their results against a gold standard, comprehensive eye examination including cycloplegic retinoscopy by licenced optometrists. We chose to target children in junior kindergarten (JK) and senior kindergarten (SK) (aged 4-5 years) because amblyopia can be treated effectively in this age range. ${ }^{1-342}$

\section{RESEARCH DESIGN AND METHODOLOGY Study design}

This is a prospective cohort study in which we chose the screening tools and referral criteria before participants were recruited and data collection began. The target sample size of 600 children was chosen based on reported prevalence of amblyopia of $3 \%-5 \%$ for children in this age range, which would yield 18-30 cases, as well as more cases of children with amblyopia risk factors.

\section{Participants}

Participants were children aged 3-6 years enrolled in a large school in Toronto, Ontario, from 2014 to 16, with 25 kindergarten classes. Many students were from immigrant families: the October 2016 student census showed that $95 \%$ of children spoke a primary language other than English at home and 37\% of families had lived in Canada for fewer than 5 years. In year 1 , there were $722 \mathrm{JK}$ and SK children who were eligible to participate. The 529 children for whom there was informed parental consent $(73 \%)$ were screened and 469 of those children subsequently received a complete gold standard eye examination with a parent or guardian present (90\% of screened children). When needed, glasses were dispensed at no cost to parents, typically about 1 month following the eye examination. In year 2, we increased the sample size by inviting parents of JK and SK children who had not participated in year 1 to participate $(\mathrm{n}=410)$. The 283 children for whom there was informed parental consent (69\%) were screened, and 243 of these children received a complete gold standard eye examination with a parent/guardian present $(87 \%$ of children screened in year 2). Data for three children from year 2 were excluded because the experimenter did not record the child's age. The final sample was 709 children (mean age $=60.4$ months, range $=46-76$ months) for whom we had complete data. For $80 \%$ of the children, the parents reported that this was their child's first eye exam (17\% reported having received an eye exam previously and $3 \%$ of parents could not remember). An additional 26 children were examined by the optometrist, but the child/parent refused cycloplegia and their data are not included in the analyses. The parents of 74 additional children consented to screening and the follow-up eye exam initially but did not attend the exams because they changed their minds (38), moved away (15), failed to arrive at the appointment (8), had scheduling conflicts (7) or were on extended vacation (6).

\section{Screening tools}

We identified five screening tools shown to be effective in detecting amblyopia and amblyopia risk factors in young children. Previous research suggests that using some combination of an acuity test, a test of binocular function (eg, stereoacuity) and an autorefractor or photoscreener is effective in detecting eye problems in young children. ${ }^{1935394344}$ Eye charts (eg, acuity and stereoacuity tests) are not reliable until age 4 years, at which point they can identify children at risk for amblyopia but miss many children with hyperopia. ${ }^{45}$ Photoscreeners and autorefractors such as the Spot (formerly Pediavision, now Welch Allyn), Plusoptix, Retinomax and SureSight (Welch Allyn) have been shown to effectively detect refractive errors in children under 6 years of age ${ }^{40}{ }^{47} \mathrm{~A}$ recently developed electronic device, the PVS, is designed to directly detect strabismus and amblyopia in children. ${ }^{41}$ The order of tests was randomised. To avoid any bias, the screeners were masked to the results of other tests.

\section{Cambridge Crowded Acuity Cards}

Because amblyopia is defined as a difference in acuity between the two eyes, ${ }^{148}$ almost any type of vision screening includes a test of monocular visual acuity. ${ }^{19} 3539$ Various acuity tests (eg, Lea symbols, HOTV and Cambridge Crowded Acuity cards) have been used with young children, but their sensitivity and specificity differ depending 
Table 1 Screening referral criteria

\begin{tabular}{|c|c|c|}
\hline \multirow[b]{2}{*}{ Screening tool } & \multicolumn{2}{|l|}{ Referral criterion } \\
\hline & 31-48 months & >48 months \\
\hline Far acuity & $<0.3 \log \mathrm{MAR}^{*}$ & $<0.2 \log M A R$ \\
\hline PVS & $<0.6$ Binocularity & $<0.6$ Binocularity \\
\hline Photoscreeners & $\begin{array}{l}\text { Hyperopia }>4.0 \mathrm{D} \text { in any meridian } \\
\text { Myopia }<-3.0 \mathrm{D} \text { in any meridian } \\
\text { Astigmatism }>2.0 \mathrm{D} \\
\text { Anisometropia }>2.0 \mathrm{D}\end{array}$ & $\begin{array}{l}\text { Hyperopia }>3.5 \mathrm{D} \text { in any meridian } \\
\text { Myopia }<-1.5 \text { in any meridian } \\
\text { Astigmatism }>1.5 \mathrm{D} \\
\text { Anisometropia }>1.5 \mathrm{D}\end{array}$ \\
\hline
\end{tabular}

${ }^{*}$ Children aged 48 months were tested against the $<0.2$ logMAR criterion for acuity.

PVS, Pediatric Vision Scanner.

on the study sample. Nevertheless, there is a consensus that crowded acuity charts are more accurate than those that use single optotypes, ${ }^{43} 49$ and some evidence suggests that crowded pictures may not be as effective in identifying amblyopia as crowded letters. ${ }^{50}$ All tests designed for young children use matching as a response measure because some children cannot yet name letters (or even some symbols). Therefore, we chose the Cambridge Crowded Acuity Cards, which use letters that are crowded by encircling letters and a matching card, tested at a distance of 3 metres. It has been used successfully with children aged 3-7 years in previous studies. ${ }^{51}{ }^{52}$ The screener began by playing the game binocularly at near, then covered the randomly chosen eye with glasses and moved back to $3 \mathrm{~m}$. Each eye was tested in turn while the fellow eye was occluded by glasses. Testing both eyes typically took 5-10 min for each child.

Plusoptix S12 (software version 6.1.10.0) and Spot (Welch Allyn; software version 2.1.4) photoscreeners

Sensitivity and specificity differ across studies, but photoscreeners have high agreement with cycloplegic retinoscopy, although they perform better in detecting astigmatism, myopia and anisometropia than hyperopia. ${ }^{4047}$ The Plusoptix S12 and Spot (Welch Allyn) photoscreeners, both of which were commercially available at the start of this study in 2014, have been shown to be particularly effective. ${ }^{404753-56}$ In one study, conducted in a paediatric ophthalmology office, Plusoptix S04 showed a sensitivity of $99 \%$ and specificity of $82 \% .{ }^{54}$ In another study, the Spot had a sensitivity of $87 \%$ and specificity of $74 \%$ for detecting clinically significant refractive errors. ${ }^{56}$ One study suggested that the Plusoptix was more accurate, but the Spot provided a reading for more children than the Plusoptix (ie, better testability), ${ }^{40}$ so we chose to include both in our screening battery. Testing with each photoscreener took 1-2 min per child.

\section{Randot preschool stereoacuity test}

Binocular function is degraded by amblyopia or eye misalignment (a risk factor for amblyopia) ${ }^{1}$ and that deficit can be manifested as reduced stereopsis. The Randot Preschool Stereoacuity Test is a widely used test that is adapted for testing children. A large-scale study of over 5000 children aged 3-18 years has provided good normative data, ${ }^{57}$ and interobserver test-retest reliability is high. ${ }^{58} \mathrm{~A}$ VIP study with lay screeners found that including a test of stereoacuity increases the ability to detect amblyopia risk factors such as strabismus. ${ }^{39}$ Testing took 2-4 min per child.

\section{The PVS}

The PVS is a new device that detects strabismus and amblyopia directly. It uses binocular retinal birefringence scanning to automatically detect strabismus as small as 1 prism dioptre (D). When tested against the presence of amblyopia and/or strabismus, the PVS demonstrated sensitivity and specificity $90 \%$ or better in previous published studies. ${ }^{4159} \mathrm{PVS}$ holds promise in detecting strabismus, amblyopia or any other medical cause of reduced three-dimensional depth perception, while minimising false referrals from moderate levels of refractive errors

\begin{tabular}{|c|c|}
\hline Disorder & Definition \\
\hline \multicolumn{2}{|l|}{ Amblyopia } \\
\hline 1.Unilateral & $\begin{array}{l}\geq 2 \text { line difference in best corrected } \\
\text { acuity and worse than } 20 / 40 \text { in any } \\
\text { eye. }\end{array}$ \\
\hline 2.Bilateral & $\begin{array}{l}\text { Worse than } 20 / 40 \text { in the better-seeing } \\
\text { eye. }\end{array}$ \\
\hline \multicolumn{2}{|l|}{ Amblyopia risk factors } \\
\hline 1.Strabismus & Tropias $>10 \mathrm{D}$ \\
\hline $\begin{array}{l}\text { 2.Reduced } \\
\text { stereoacuity }\end{array}$ & $>100$ arcsec \\
\hline 3. Refractive errors & As defined below \\
\hline a.Hyperopia & $>3.5 \mathrm{D}$ \\
\hline b.Myopia & $<-1.5 \mathrm{D}$ \\
\hline c.Astigmatism & $>1.5 \mathrm{D}$ \\
\hline d.Anisometropia & $>1.5 \mathrm{D}$ \\
\hline
\end{tabular}

D, dioptre. 


\begin{tabular}{lc}
\hline Table 3 & Prevalence of eye problems \\
\hline Disorder & $\mathbf{n}$ (\% screened) \\
\hline Any problem & $188(26.5)$ \\
Amblyopia & $42(5.9)$ \\
Unilateral & $24(3.4)$ \\
Bilateral & $18(2.5)$ \\
Amblyopia risk factors & $170(24.0)$ \\
Strabismus & $28(3.9)$ \\
Reduced stereoacuity & $35(4.9)$ \\
Hyperopia & $38(5.4)$ \\
Myopia & $10(1.4)$ \\
Astigmatism & $101(14.2)$ \\
Anisometropia & $8(1.1)$ \\
Other problems & $5(0.1)$
\end{tabular}

If a child had more than one problem, he/she was counted repeatedly in each applicable category ( 26 children had both amblyopia and a risk factor or other problem).

that do not require treatment. The PVS has not been evaluated in any large-scale study for use in a vision screening programme aimed at detecting any vision problem in a population-based sample or in combination with other tests. Testing took 1-2 min per child.

\section{Classification of vision screening test results}

Children who met the referral criteria for any test (table 1) were considered a 'refer', whereas only children who passed all five tests were considered a 'pass'. Referral criteria for visual acuity and refractive errors were based on the 2013 American Association for Pediatric Ophthalmology and Strabismus (AAPOS) vision screening guidelines. ${ }^{60}$ The preprogrammed referral thresholds on the Plusoptix did not match these AAPOS guidelines, and thus screeners were trained to manually make the decision of pass/refer based on the refractive error values. The referral criterion for visual acuity for children $<48$ months were made more lenient based on the recommended guidelines and normative data in the literature. ${ }^{445161}$ The referral criterion for the Randot Preschool Stereoacuity Test was based on previously published normative data. ${ }^{57}$ For the PVS, we followed the manufacturers' guidelines (failure to fixate binocularly on at least $60 \%$ of 10 attempted measurements $).{ }^{41}$ Children who did not understand a test or who were uncooperative were considered a 'refer', as previous research suggests that these children are at higher risk of having a vision disorder. $^{62}$

\section{Gold standard eye examinations}

Each child received a gold standard comprehensive eye examination, including cycloplegic refraction, by a licensed optometrist. The exams were typically conducted 1 month after screening, and the optometrists were masked to the screening results of each child. An examination lane was set up at the school, and examinations occurred with parents/guardians present. The following tests were performed: monocular visual acuity at near and far (HOTV or Snellen letters, or Lea picture symbols), colour vision (Hardy-Rand-Rittler Test), ocular motility (versions and ductions), ocular alignment (cover test), binocular function (Preschool Randot or Titmus stereo test, motor fusion), anterior segment (using a slit lamp), cycloplegic refraction (cyclopentolate $1 \%$ and phenylephrine $2.5 \%$ ) and dilated fundus examination. Glasses were provided at no cost to the family when prescribed.

\section{Definition of amblyopia and clinically significant refractive errors}

The definition of amblyopia and its risk factors, including clinically significant refractive errors, are shown in table 2, and are based on the guidelines of the American Academy of Ophthalmology and AAPOS for children aged 31-72 months. ${ }^{160}$ Optometrists made clinical judgments about whether a child should receive treatment (eg, glasses) independently from these research definitions. Prescribing practices vary among clinicians, and thus 'number of glasses prescribed' was not an a priori variable of interest in our study.

\section{Data analyses}

Data from 709 children for whom there were complete gold standard eye examination results were used to determine the prevalence of vision problems, as well as the diagnostic capability of the five screening tools. Sensitivity, specificity, positive predictive value (PPV) and negative predictive value (NPV) were computed by comparing the screening diagnosis ('pass' vs 'refer') to the findings from the comprehensive eye examination (ie, problem present vs not present). These measures were computed for each screening tool independently as well as for all

Table 4 Results obtained from the five screening tools compared to the results of the comprehensive eye examination with cycloplegic refraction by a licenced optometrist

\section{Comprehensive eye examination}

\begin{tabular}{|c|c|c|c|c|c|c|c|}
\hline \multirow[b]{3}{*}{ Screening } & \multicolumn{6}{|c|}{ Comprenensive eye examination } & \multirow[b]{3}{*}{ Grand tota } \\
\hline & \multicolumn{3}{|c|}{ Junior kindergarten } & \multicolumn{3}{|c|}{ Senior kindergarten } & \\
\hline & Any problem & No problem & Total & Any problem & No problem & Total & \\
\hline Refer & 100 & 179 & 279 & 58 & 87 & 145 & 285 \\
\hline Pass & 23 & 140 & 163 & 7 & 115 & 122 & 424 \\
\hline Total & 123 & 319 & 442 & 65 & 202 & 267 & 709 \\
\hline
\end{tabular}


Table 5 Diagnostic capabilities of the screening tools for detecting any vision problem (95\% Cls based on bootstrapping are shown in parentheses)

\begin{tabular}{lllll}
\hline Screening tool & Sensitivity & Specificity & PPV & NPV \\
\hline All five tools & $0.84(0.78$ to 0.89$)$ & $0.50(0.44$ to 0.53$)$ & $0.37(0.33$ to 0.42$)$ & $0.90(0.86$ to 0.93$)$ \\
Cambridge crowded acuity & $0.59(0.51$ to 0.65$)$ & $0.73(0.69$ to 0.76$)$ & $0.44(0.38$ to 0.50$)$ & $0.83(0.79$ to 0.86$)$ \\
Randot preschool & $0.33(0.27$ to 0.40$)$ & $0.90(0.88$ to 0.93$)$ & $0.55(0.46$ to 0.64$)$ & $0.79(0.75$ to 0.82$)$ \\
Plusoptix photoscreener & $0.64(0.57$ to 0.71$)$ & $0.88(0.84$ to 0.90$)$ & $0.65(0.58$ to 0.71$)$ & $0.87(0.84$ to 0.90$)$ \\
Spot photoscreener & $0.60(0.53$ to 0.66$)$ & $0.93(0.91$ to 0.95$)$ & $0.76(0.68$ to 0.83$)$ & $0.86(0.84$ to 0.89$)$ \\
Paediatric vision scanner & $0.41(0.33$ to 0.47$)$ & $0.77(0.73$ to 0.80$)$ & $0.38(0.32$ to 0.45$)$ & $0.78(0.74$ to 0.81$)$ \\
\hline
\end{tabular}

NPV, negative predictive value; PPV, positive predictive value.

possible combinations, along with $95 \%$ CIs, using a bootstrapping method that randomly sampled two-thirds of the data 2000 times. We also conducted an exploratory analysis by splitting the outcomes into JK versus SK children. In addition, we conducted ROC analyses using SPSS software (V.25) for each screening tool as an added measure of diagnostic accuracy, as well as to evaluate the appropriateness of the referral criteria.

\section{Patient and public involvement}

A researcher from the Toronto District School Board (TDSB), the principal and vice principal at the study site and the central principals of the Model Schools for Inner Cities (MSIC) programme of the TDSB (a programme that services low-income neighbourhoods) advised on the design of the study, recruitment and consent material for parents and logistics of running the study. Parents of eligible kindergarten children were consulted at a beginning-of-school-year event. A summary of the findings was shared with the principal and vice principal at the study site, lead principals of the MSIC and the TDSB research ethics board. The full research report, as well as general information relevant to parents, have been made available to the public via our website: www.visionscreening.ca

\section{RESULTS}

Of the 709 children for whom there were complete screening and gold standard eye exam data, $26.5 \%$ had a vision problem as defined in table 2. The prevalence of each type of problem is shown in table 3 , with $5.9 \%$ of children having amblyopia and $24.0 \%$ having an amblyopia risk factor, the most common of which was astigmatism $(14.2 \%)$. The 'other' problems $(0.1 \%)$ consisted of four cases of nystagmus and a single case of optic nerve abnormality. table 4 shows the screening results (from all five tools) against the results of the comprehensive eye examination.

Table 5 shows the sensitivity, specificity, PPV and NPV for detecting a vision problem for all five tools combined, as well as for each tool separately. Because a child was considered 'refer' if he or she failed any one of the tests, sensitivity was highest $(84 \%, 95 \%$ CI 78 to 89$)$ but specificity was lowest $(49 \%, 95 \%$ CI 44 to 53$)$ when all five tools were combined. Individually, the Plusoptix had the highest sensitivity (64\%, 95\% CI 57 to 71$)$ and the Spot had the highest specificity (93\%, 95\% CI 91 to 95 ).

As an exploratory analysis, we also conducted logistic regression analyses to determine whether the accuracy of the screening tools differed when used with children in JK (mean age $=55.6$ months; range $=46-64$ months) versus SK (mean age $=68.2$ months; range $=53-76$ months). The estimated odds of having a correct screening result in SK were 1.52 times (95\% CI 1.11 to 2.08) those in JK, suggesting that screening was more accurate with SK children. Sensitivity and specificity for the two age groups are shown separately in table 6 .

Table 6 Diagnostic capabilities of the screening tools for detecting any vision problem for children in junior kindergarten (JK) and senior kindergarten (SK)

\begin{tabular}{llllll}
\hline Screening tool & Sensitivity & & \multicolumn{2}{l}{ Specificity } \\
\cline { 1 - 2 } \cline { 5 - 6 } Grade & JK & SK & JK & SK \\
\hline All five tools & $0.81(0.73$ to 0.88$)$ & $0.89(0.80$ to 0.96$)$ & & $0.44(0.39$ to 0.50$)$ & $0.57(0.50$ to 0.64$)$ \\
Cambridge Crowded Acuity & $0.59(0.50$ to 0.68$)$ & $0.57(0.45$ to 0.69$)$ & & $0.68(0.63$ to 0.73$)$ & $0.81(0.75$ to 0.86$)$ \\
Randot Preschool & $0.37(0.28$ to 0.45$)$ & $0.26(0.16$ to 0.37$)$ & & $0.88(0.84$ to 0.92$)$ & $0.93(0.89$ to 0.96$)$ \\
Plusoptix Photoscreener & $0.60(0.51$ to 0.69$)$ & $0.71(0.58$ to 0.81$)$ & & $0.86(0.82$ to 0.90$)$ & $0.90(0.84$ to 0.94$)$ \\
Spot Photoscreener & $0.55(0.46$ to 0.64$)$ & $0.68(0.55$ to 0.78$)$ & & $0.93(0.89$ to 0.95$)$ & $0.95(0.90$ to 0.97$)$ \\
Pediatric Vision Scanner & $0.37(0.29$ to 0.46$)$ & $0.48(0.36$ to 0.60$)$ & & $0.74(0.70$ to 0.79$)$ & $0.80(0.74$ to 0.85$)$ \\
\hline
\end{tabular}

95\% Cls based on bootstrapping are shown in parentheses. 
Table 7 Diagnostic capabilities of different combinations of screening tools for detecting any vision problem (95\% Cls are shown in parentheses)

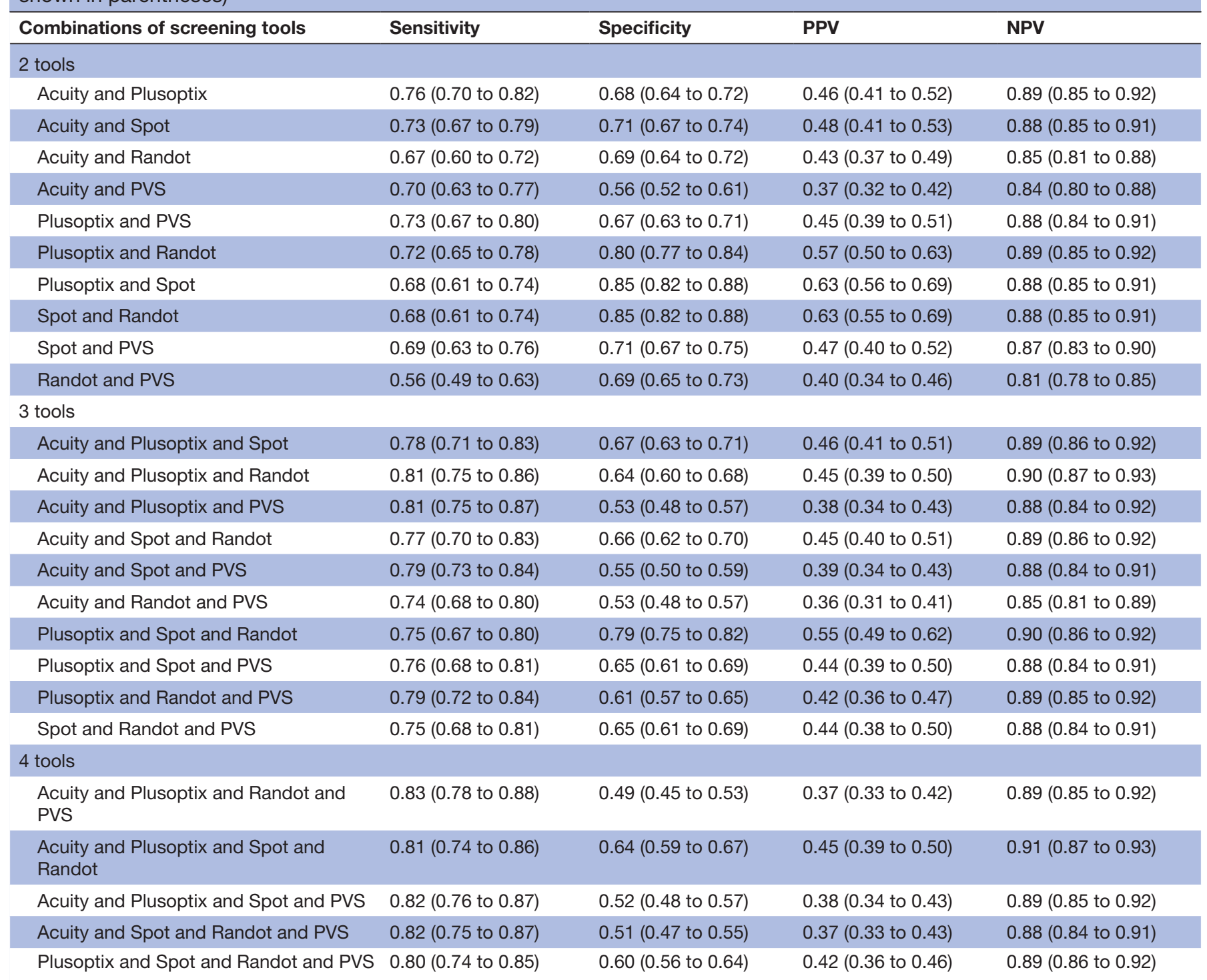

PVS, pediatric vision scanner.

Additionally, we compared bootstrapped estimates of sensitivity, specificity, PPV and NPV for all possible combinations of the screening tools. The results are summarised in table 7. Understanding how sensitivity and specificity differ with the addition or deletion of a screening tool has important consequences for policy makers, because using fewer tests without significantly lowering sensitivity and specificity makes most economic sense. Our analyses reveal that the combination of the three tools of Cambridge Crowded Acuity Cards, Randot Preschool stereotest and Plusoptix had a sensitivity of $81 \%$ and specificity of $64 \%$, which is comparable with the results using four or five tools, suggesting that such a combination would be ideal to keep costs down. As would be expected, using only the PVS and Randot had the worst sensitivity of $56 \%$ because neither test is designed to effectively detect refractive errors. The Plusoptix and Spot seem to perform similarly, although using both improved sensitivity from 60\% (Spot only) and 64\% (Plusoptix only) to $68 \%$ while maintaining specificity at $85 \%$, indicating that the two photoscreeners do not always detect the same problems. A direct comparison of the performance of the Plusoptix and Spot revealed that the two photoscreeners agreed in $89 \%(633 / 709)$ of cases. Of the 57 cases in which the Plusoptix referred but the Spot passed a child, 16 had a problem $(2.3 \%$ of screened children had a problem missed by the Spot), whereas 41 did not have a problem (Plusoptix had over-referred). Of the 19 cases in which the Spot had referred but the Plusoptix passed a child, 6 had a problem $(0.8 \%$ of children screened had a problem missed by the Plusoptix) and 13 did not have a problem (Spot had over-referred).

Testability was high for all tools: Cambridge Crowded Acuity $97.5 \%$, Plusoptix 94.8\%, Spot 99.5\%, Randot 
Table 8 Area under the curve (AUC) values from ROC analyses of each screening tool

\begin{tabular}{|c|c|c|c|c|c|}
\hline Screening tool & Target disorder & $\mathbf{n}$ & AUC & $95 \% \mathrm{Cl}$ & Significance \\
\hline Acuity & Any problem & 691 & 0.685 & 0.637 to 0.733 & $\mathrm{p}<0.001$ \\
\hline Plusoptix - cylinder & Any problem & 672 & 0.822 & 0.784 to 0.860 & $\mathrm{p}<0.001$ \\
\hline Spot - cylinder & Any problem & 707 & 0.836 & 0.799 to 0.874 & $p<0.001$ \\
\hline Spot - SE & Any problem & 707 & 0.537 & 0.482 to 0.592 & $p=0.13$ \\
\hline PVS & Any problem & 699 & 0.610 & 0.562 to 0.658 & $\mathrm{p}<0.001$ \\
\hline Plusoptix - SE & Hyperopia & 672 & 0.856 & 0.790 to 0.923 & $\mathrm{p}<0.001$ \\
\hline Spot - SE & Hyperopia & 707 & 0.886 & 0.817 to 0.954 & $\mathrm{p}<0.001$ \\
\hline PVS & Strabismus & 699 & 0.654 & 0.554 to 0.754 & $\mathrm{p}<0.01$ \\
\hline
\end{tabular}

PVS, pediatric vision scanner; SE, spherical equivalent.

97.9\% and PVS $98.6 \%$. While the overall prevalence of having a visual problem was $26.5 \%$, there was a higher proportion of children with a visual problem among the children who were unable to complete a test: Cambridge Crowded Acuity $33.3 \%$, Randot $40.0 \%$, Plusoptix $64.9 \%$, Spot $50.0 \%$ and PVS $40.0 \%$. These results suggest that screening programmes should refer any child who is unable to complete a test for a comprehensive eye examination.

We conducted ROC analyses based on the results for each screening tool tested against the presence/absence

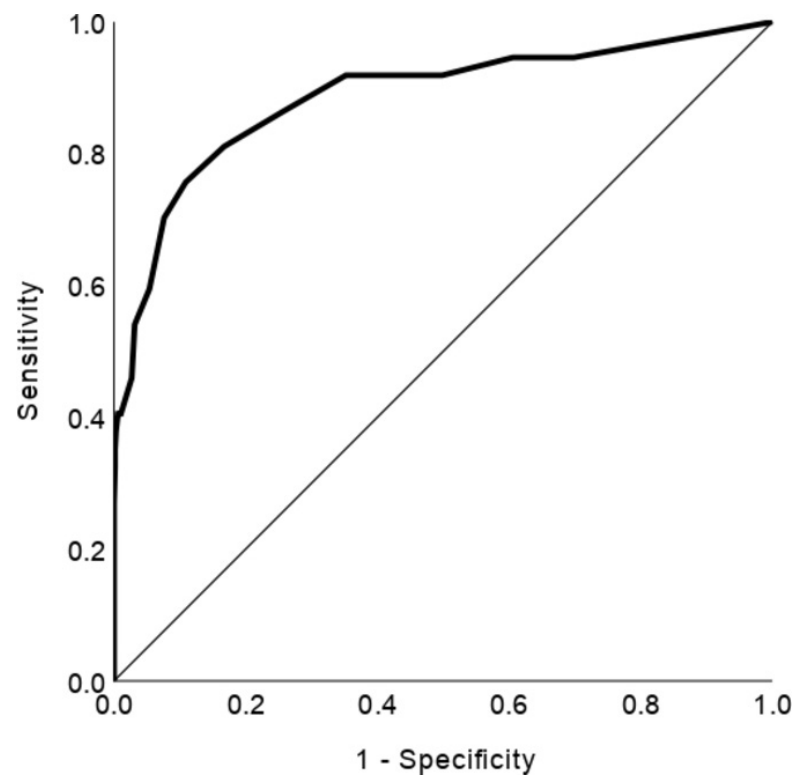

Figure 1 ROC of spot SE values tested against the presence of hyperopia as determined in a gold standard eye exam by a licenced optometrist $(\mathrm{AUC}=0.89)$. The curved line shows how sensitivity and specificity varies with different SE values (specificity is plotted as 1 - specificity on the $\mathrm{x}$-axis). The diagonal line represents a test with no diagnostic accuracy (ie, $50 \%$ chance that the test correctly diagnosed the disease); the extent to which the curve deviates from the diagonal indicates the accuracy of the test and is quantified as area under the curve (AUC). SE, spherical equivalent. of any visual problem and also for specific target disorders that the screening tool was designed to detect. The area under the curve (AUC) provides a measure for comparing the diagnostic accuracies of the screening tools, and these values are summarised in table 8 (children who were not able to complete a test were excluded from these analyses). The highest AUC value was found for the spherical equivalent (SE) values from the Spot tested against the presence of hyperopia and the ROC is shown in figure 1 . The AUC values provide converging evidence that overall, the two photoscreeners had the highest accuracy, although this is likely because they are designed to detect astigmatism (by the cylinder values), the most common disorder found in our sample. Acuity had better diagnostic power than the Randot and the PVS, likely because they were designed to detect amblyopia and binocular vision disorders, not refractive errors such as astigmatism. This also explains the low AUC value for the SE from the photoscreeners. When tested against the target disorder for which they were designed (SE from photoscreeners against hyperopia and PVS against strabismus), the AUC values are higher. There were too few cases of myopia and anisometropia to be considered separately.

Based on these ROC analyses, table 9 provides sensitivity and specificity values for detecting any visual disorder using different referral cut-offs for each tool. Together with tables 6 and 7, these tables provide a reference for choosing the appropriate screening tool(s) and referral criteria depending on the availability of resources (ie, whether the emphasis is on not missing visual problems or not over-referring for unnecessary eye exams). We also provide sensitivity and specificity values for the photoscreeners and PVS for detecting the specific disorders that they were designed to detect in online supplementary table 1. In regions/countries where there is universal healthcare, it may be beneficial to optimise sensitivity, even at the cost of lower specificity, so that more children enter into optometry care and few problems are missed. In contrast, in regions where resources are scarce, it may 
Table 9 Sensitivity and specificity values at different referral cut-offs for each screening tool

\begin{tabular}{|c|c|c|c|}
\hline Test & $\begin{array}{l}\text { Refer if worse } \\
\text { than or equal to }\end{array}$ & Sensitivity & Specificity \\
\hline \multirow[t]{5}{*}{ Acuity } & $6 / 9$ & 1.0 & 0 \\
\hline & $6 / 12$ & 0.60 & 0.72 \\
\hline & $6 / 18$ & 0.33 & 0.92 \\
\hline & $6 / 24$ & 0.08 & 0.99 \\
\hline & $<6 / 24$ & 0.02 & 1.0 \\
\hline \multirow{7}{*}{$\begin{array}{l}\text { Plusoptix } \\
\text { (cylinder) }\end{array}$} & 0.50 & 0.94 & 0.27 \\
\hline & 0.75 & 0.89 & 0.49 \\
\hline & 1.0 & 0.80 & 0.68 \\
\hline & 1.25 & 0.74 & 0.77 \\
\hline & 1.5 & 0.69 & 0.85 \\
\hline & 1.75 & 0.59 & 0.90 \\
\hline & 2.0 & 0.54 & 0.92 \\
\hline \multirow{7}{*}{$\begin{array}{l}\text { Spot } \\
\text { (cylinder) }\end{array}$} & 0.50 & 0.97 & 0.16 \\
\hline & 0.75 & 0.90 & 0.44 \\
\hline & 1.0 & 0.82 & 0.68 \\
\hline & 1.25 & 0.72 & 0.81 \\
\hline & 1.5 & 0.64 & 0.89 \\
\hline & 1.75 & 0.56 & 0.93 \\
\hline & 2.0 & 0.48 & 0.97 \\
\hline \multirow[t]{4}{*}{ Randot } & 100 & 1.0 & 0 \\
\hline & 200 & 0.31 & 0.92 \\
\hline & 400 & 0.15 & 0.97 \\
\hline & 800 & 0 & 1.0 \\
\hline \multirow[t]{5}{*}{ PVS } & 1.0 & 1.0 & 0 \\
\hline & 0.8 & 0.73 & 0.42 \\
\hline & 0.6 & 0.55 & 0.60 \\
\hline & 0.4 & 0.39 & 0.78 \\
\hline & 0.2 & 0.35 & 0.82 \\
\hline
\end{tabular}

PVS, pediatric vision scanner.

be more cost effective to target high specificity to minimise false referrals.

\section{DISCUSSION}

The goal of the current study was to assess the diagnostic capabilities of different screening tools that are appropriate for typically developing kindergarten children. We found that $5.9 \%$ of children had amblyopia and $24.0 \%$ had amblyopia risk factors. These rates are similar to those from a previous screening programme conducted in Toronto that included over 10000 students in the early grades (although no examinations were conducted on children who passed screening) ${ }^{63}$ as well as other studies conducted in Newfoundland (Canada), USA, Australia, Singapore and China. ${ }^{12-22}$ Overall, the current battery revealed a sensitivity of $84 \%$ but a specificity of $49 \%$. The results indicate that by using all five tools, vision problems are not likely to be missed but roughly half of the children referred for a full eye examination would not have an eye problem. Importantly, parents reported that for $80 \%$ of children in our sample, this was their first optometry exam. Without such a school-based screening programme, the children with amblyopia and its risk factors might not have been identified until it was too late for treatment to be effective.

The optimal set of screening tools will depend on available resources as well as the social and political climate of a given jurisdiction. Adding more tests will result in fewer missed problems (higher sensitivity) but more over-referrals (lower specificity), which can overburden clinicians unnecessarily where access to eye care may be difficult. For example, the VIP study in the USA examined how sensitivity of the screening tests changed with specificity targeted at $90 \%^{19} 39$ and $94 \%^{64}$ to prevent unnecessary referrals. In our data, both the Plusoptix and Spot photoscreeners had high specificity, above $90 \%$, for SK children and reasonable sensitivity (around 70\%). This finding, in part, may be because our sample had a high prevalence of astigmatism, which photoscreeners detect more accurately than they do hyperopia or myopia. ${ }^{40} 4753$ Consistent with the findings from the autorefractor/photoscreener used in phase 1 of the VIP study, ${ }^{19}{ }^{39}$ there appears to be little advantage to using both the Plusoptix and the Spot. Adding the PVS to detect amblyopia and strabismus appears to improve sensitivity. We used the Cambridge Crowded Acuity Cards in our current study, whereas other preschool screening studies have used HOTV or Lea symbols. We do not expect the results to differ depending on the type of acuity test used, as long as an age-appropriate crowded acuity test is used that uses matching and presents each letter/symbol individually (eg, Cambridge Crowding Cards, HOTV Hand-Held 50\% Crowded Book and Lea Symbols Crowded Symbol Book), because single-letter acuity tests without crowding are less sensitive in identifying individuals with amblyopia. The bootstrapping analyses indicate that the combined tools are more accurate in detecting vision problems in senior kindergarten children ( 5 year olds) than in JK children (4 year olds). Importantly, we provide sensitivity and specificity values for varying referral cut-offs from the ROC analyses so that policy makers can make their own decisions for their screening programme about the age at which to implement, which tools to use and which cutoffs to use for referrals.

In pilot work, we found that most children failed the two behavioural tests (visual acuity and stereoacuity) if we started testing at the referral threshold. Thus, we chose to begin with the easiest levels (largest letters of 6/60 for acuity testing and largest discrepancy of 800 arcsec for stereoacuity) and to work towards more difficult levels until children made mistakes. We believe that this is an important strategy for school-based vision screening so that the screeners have time to build rapport with the children and to engage the child with the 'games'. Although only two of the five screening tests required a verbal response, it is possible that some children failed more from fatigue than an actual visual problem as they went through the later tests. 
The order of tests was counterbalanced, and there was no systematic effect of order on referral rate for any test, with referral rates ranging from $2 \%$ (children who completed Randot second) to $8 \%$ (children who completed acuity as their first test and as their fourth test). However, fatigue may account for the lower accuracy of the screening tools in JK compared with SK children, a result suggesting that fewer tests may be advantageous for that age group and not just from a cost-savings perspective.

One limitation of our study is that we may have overestimated the prevalence of amblyopia (5.9\%) because it sometimes resolves quickly after spectacle correction. Although acuity was remeasured at the time the child received the glasses, follow-up assessments were not made. Had they been possible, the prevalence of amblyopia might have been lower. Nevertheless, those cases would still have been included in the count of children identified as having eye problems requiring treatment. Another limitation is the lack of demographic data that might help explain the high percentage of screened children $(26.5 \%)$ found to have a visual problem. The school serves an immigrant community, and it is known that race and ethnicity affect prevalence rates of refractive errors. For example, astigmatism is more common among Native American, African American and Hispanic children compared with non-Hispanic white children. ${ }^{656}$ Finally, as one would expect from a sample of children aged 4 and 5 years, we had too few cases of myopia and anisometropia to conduct meaningful ROC analyses.

In summary, the current study showed that conducting vision screening and follow-up gold standard eye examinations can effectively detect eye problems in children before they enter grade 1 . Our screening tools consisting of crowded visual acuity, photoscreeners, stereoacuity and a device measuring eye alignment, correctly referred $84 \%$ of children aged 3-6 who had a vision problem (89\% for those 5-6). These results support implementation of a similar vision screening programme in or before senior kindergarten, in communities where none exists. Future research should include a health economic analysis of the costs and benefits associated with such a screening programme.

Acknowledgements The authors would like to thank the Gift of Sight \& Sound Program of the non-profit organisation Toronto Foundation for Student Success for organising screeners, optometrists and opticians, as well as for arranging free glasses for the children donated by Clearly. The authors would also like to thank Muhammad Mamdani, director (Applied Health Research Centre, Li Ka Shing Knowledge Institute of St. Michael's Hospital) and professor (University of Toronto), and Maria Yau, research co-ordinator (Research \& Development, Toronto District School Board) for their contribution in the design of the study. We would also like to thank David Hunter and Justin Shaka for the loan of a Pediatric Vision Scanner, and Mano Chandrakumar, Sally Stafford and Naemah Abid for their assistance with the logistics of the study.

Contributors MN is the first author, assembled, cleaned and analysed the data, interpreted results and wrote and revised the manuscript. AW and DM are senior authors; they devised the project, supervised data collection, interpreted the results critically and revised the manuscript. AC and KT are the biostatisticians who estimated sample size and carried out the bootstrapping analyses. All authors had full access to the data in the study and can take responsibility for its integrity and accuracy of the analyses. The authors attest that all listed authors meet authorship criteria and that no others meeting the criteria have been omitted.
Funding This research was supported by a Collaborative Health Research Project grant from Canadian Institutes of Health Research and Natural Sciences and Engineering Research Council of Canada to DM and AW, a Joanne Angle Investigator Award from Prevent Blindness America to AW and private donations.

Competing interests None declared.

Patient consent for publication Not required.

Provenance and peer review Not commissioned; externally peer reviewed.

Data availability statement The full data set is available on request from the corresponding author at mayu.nishimura@sickkids.ca or senior author DM at maurer@mcmaster.ca until 7 years after publication, at which time the data will be destroyed and deleted securely in accordance with data management policies of SickKids Hospital (Toronto, Canada).

Open access This is an open access article distributed in accordance with the Creative Commons Attribution Non Commercial (CC BY-NC 4.0) license, which permits others to distribute, remix, adapt, build upon this work non-commercially, and license their derivative works on different terms, provided the original work is properly cited, appropriate credit is given, any changes made indicated, and the use is non-commercial. See: http://creativecommons.org/licenses/by-nc/4.0/.

\section{REFERENCES}

1. American Academy of Ophthalmology Pediatric Ophthalmology/ Strabismus Panel. Preferred practice Pattern $®$ guidelines. Amblyopia. San Francisco, CA: American Academy of Opthalmology, 2012. www.aao.org/ppp

2. Stewart CE, Fielder AR, Stephens DA, et al. Treatment of unilateral amblyopia: factors influencing visual outcome. Invest Ophthalmol Vis Sci 2005;46:3152-60.

3. Wu C, Hunter DG. Amblyopia: diagnostic and therapeutic options. Am J Ophthalmol 2006;141:175-84.

4. Simons K, Preslan M. Natural history of amblyopia untreated owing to lack of compliance. Br J Ophthalmol 1999;83:582-7.

5. Attebo K, Mitchell P, Cumming R, et al. Prevalence and causes of amblyopia in an adult population. Ophthalmology 1998;105:154-9.

6. Tommila V, Tarkkanen A. Incidence of loss of vision in the healthy eye in amblyopia. Br J Ophthalmol 1981;65:575-7.

7. Rahi JS, Logan S, Timms C, et al. Risk, causes, and outcomes of visual impairment after loss of vision in the non-amblyopic eye: a population-based study. The Lancet 2002;360:597-602.

8. van Leeuwen R, Eijkemans MJC, Vingerling JR, et al. Risk of bilateral visual impairment in individuals with amblyopia: the Rotterdam study. Br J Ophthalmol 2007;91:1450-1.

9. Grant S, Moseley MJ. Amblyopia and real-world visuomotor tasks. Strabismus 2011;19:119-28.

10. Kelly KR, Jost RM, De La Cruz A, et al. Amblyopic children read more slowly than controls under natural, binocular reading conditions. $J$ AAPOS 2015;19:515-20.

11. Stifter E, Burggasser G, Hirmann E, et al. Monocular and binocular reading performance in children with microstrabismic amblyopia. $\mathrm{Br}$ J Ophthalmol 2005;89:1324-9.

12. Multi-ethnic Pediatric Eye Disease Study Group. Prevalence of amblyopia and strabismus in African American and Hispanic children ages 6 to 72 months. Ophthalmology 2008;115:1229-36.

13. McKean-Cowdin R, Cotter SA, Tarczy-Hornoch K, et al. Prevalence of amblyopia or strabismus in Asian and non-Hispanic white preschool children: multi-ethnic pediatric eye disease study. Ophthalmology 2013;120:2117-24.

14. Friedman DS, Repka MX, Katz J, et al. Prevalence of amblyopia and strabismus in white and African American children aged 6 through 71 months the Baltimore pediatric eye disease study. Ophthalmology 2009;116:2128-34.

15. Chia A, Dirani M, Chan Y-H, et al. Prevalence of amblyopia and strabismus in young singaporean Chinese children. Invest Ophthalmol Vis Sci 2010;51:3411-7.

16. Chen X, Fu Z, Yu J, et al. Prevalence of amblyopia and strabismus in Eastern China: results from screening of preschool children aged 36-72 months. Br J Ophthalmol 2016;100:515-9.

17. Pascual M, Huang J, Maguire MG, et al. Ying Gs: vision in preschoolers (VIP) Study Group. risk factors for amblyopia in the vision in preschoolers study. Ophthalmolology 2014;121:622-9.

18. Drover JR, Kean PG, Courage ML, et al. Prevalence of amblyopia and other vision disorders in young Newfoundland and Labrador children. Can J Ophthalmol 2008;43:89-94.

19. Schmidt P, Maguire MG, Dobson V, et al. Comparison of preschool vision screening tests as administered by licensed eye care 
professionals in the vision in preschoolers study. Am Acad Ophthalmol 2004;111:637-50

20. Huang J, Maguire MG, Ciner E, et al. Risk factors for astigmatism in the vision in preschoolers study. Optom Vis Sci 2014:91:514-21.

21. Wen G, Tarczy-Hornoch K, McKean-Cowdin R, et al. Prevalence of myopia, hyperopia, and astigmatism in non-Hispanic white and Asian children: multi-ethnic pediatric eye disease study. Ophthalmology 2013;120:2109-16.

22. Giordano L, Friedman DS, Repka MX, et al. Prevalence of refractive error among preschool children in an urban population: the Baltimore pediatric eye disease study. Ophthalmology 2009;116:739-46.

23. Simons HD, Gassler PA. Vision anomalies and reading skill: a metaanalysis of the literature. Optom Vis Sci 1988;65:893-904.

24. Stewart-Brown S, Haslum MN, Butler N. Educational attainment of 10-year-old children with treated and untreated visual defects. Dev Med Child Neurol 1985;27:504-13.

25. Kulp MT, Schmidt PP. Visual predictors of reading performance in kindergarten and first grade children. Optom Vis Sci 1996;73:255-62.

26. Shankar S, Evans MA, Bobier WR. Hyperopia and emergent literacy of young children: pilot study. Optom Vis Sci 2007;84:1031-8.

27. Kulp MT, Ciner E, Maguire M, et al. Uncorrected Hyperopia and Preschool Early Literacy. Ophthalmology 2016;123:681-9.

28. Hopkins S, Sampson GP, Hendicott PL, et al. Vision problems and reduced reading outcomes in Queensland schoolchildren. Optom Vis Sci 2017;94:345-52.

29. Harvey EM, Miller JM, Twelker JD, et al. Reading fluency in school-aged children with bilateral astigmatism. Optom Vis $\mathrm{Sci}$ 2016;93:118-25

30. Roch-Levecq A-C, Brody BL, Thomas RG, et al. Ametropia, preschoolers' cognitive abilities, and effects of spectacle correction. Arch Ophthalmol 2008;126:252-8.

31. Eibschitz-Tsimhoni M, Friedman T, Naor J, et al. Early screening for amblyogenic risk factors lowers the prevalence and severity of amblyopia. J AAPOS 2000;4:194-9.

32. Williams C, Northstone K, Harrad RA. Amblyopia treatment outcomes after screening before or at age 3 years: follow up from randomised trial. BMJ 2002;324.

33. Williams C, Northstone K, Harrad RA, et al. Amblyopia treatment outcomes after preschool screening $\mathrm{V}$ school entry screening: observational data from a prospective cohort study. $\mathrm{Br} J$ Ophthalmol 2003;87:988-93

34. Chou R, Dana T, Bougatsos C. Screening for visual impairment in children ages 1-5 years: update for the USPSTF. Pediatrics 2011;127:e442-79.

35. Grossman DC, Curry SJ, Owens DK, et al. Vision screening in children aged 6 months to 5 years: US preventive services Task force recommendation statement. JAMA 2017;318:836-44.

36. Jonas DE, Amick HR, Wallace IF, et al. Vision screening in children aged 6 months to 5 years: evidence report and systematic review for the US preventive services Task force. JAMA 2017;318:845-58.

37. Snowdon SK, Stewart-Brown SL. Preschool vision screening. Health Technol Assess 1997;1:1-98.

38. Schmucker C, Grosselfinger R, Riemsma R, et al. Effectiveness of screening preschool children for amblyopia: a systematic review. BMC Ophthalmol 2009;9:1-12.

39. Vision in Preschoolers Study Group. Preschool vision screening tests administered by nurse screeners compared with lay screeners in the vision in preschoolers study. Invest Ophthalmol Vis Sci 2005;46:2639-48.

40. Peterseim MMW, Papa CE, Wilson ME, et al. Photoscreeners in the pediatric eye office: compared testability and refractions on high-risk children. Am J Ophthalmol 2014;158:932-8.

41. Loudon SE, Rook CA, Nassif DS, et al. Rapid, high-accuracy detection of strabismus and amblyopia using the pediatric vision scanner. Invest Ophthalmol Vis Sci 2011;52:5043-8.

42. Keech RV, Kutschke PJ. Upper age limit for the development of amblyopia. J Pediatr Ophthalmol Strabismus 1995;32:89-93.

43. Moseley MJ, Fielder AR, Screening PV. Preschool vision screening. Br J Ophthalmol 2003;87.

44. Cotter SA, Cyert LA, Miller JM, et al. Vision screening for children 36 to $<72$ months: recommended practices. Optom Vis Sci 2015;92:6-16.
45. Mognasewari D, Thomas J, Srinivasan K. Jacob GP. test re-test reliability and validity of different visual acuity and stereoacuity charts used in preschool children. J or Clin Diagnostic Res 2015;9:NC01NC05.

46. Langeslag-Smith MA, Vandal AC, Briane V, et al. Preschool children's vision screening in New Zealand: a retrospective evaluation of referral accuracy. BMJ Open 2015;5:e009207.

47. Fogel-Levin M, Doron R, Wygnanski-Jaffe T, et al. A comparison of plusoptiX A12 measurements with cycloplegic refraction. J AAPOS 2016;20:310-4.

48. The Lasker/IRRF Initiative for Innovation in Vision Science. Amblyopia: challenges and opportunities, 2017.

49. Morad Y, Werker E, Nemet P. Visual acuity tests using chart, line, and single optotype in healthy and amblyopic children. J Aapos 1999;3:94-7

50. O'Boyle C, Chen SI, Little J-A. Crowded letter and crowded picture logMAR acuity in children with amblyopia: a quantitative comparison Br J Ophthalmol 2017;101:457-61.

51. Atkinson J, Anker S, Evans C, et al. Visual acuity testing of young children with the Cambridge crowding cards at 3 and 6 M. Acta Ophthalmol 1988:66:505-8.

52. Atkinson J, Braddick O, Nardini M, et al. Infant hyperopia: detection, distribution, changes and correlates-outcomes from the Cambridge infant screening programs. Optom Vis Sci 2007;84:84-96.

53. $\mathrm{Mu} \mathrm{Y,} \mathrm{Bi} \mathrm{H,} \mathrm{Ekure} \mathrm{E,} \mathrm{et} \mathrm{al.} \mathrm{Performance} \mathrm{of} \mathrm{spot} \mathrm{photoscreener} \mathrm{in}$ detecting amblyopia risk factors in Chinese pre-school and school age children attending an eye clinic. PLoS ONE 2016;11:e0149561.

54. Matta NS, Singman EL, Silbert DI. Performance of the plusoptiX S04 photoscreener for the detection of amblyopia risk factors in children aged 3 to 5. J AAPOS 2010;14:147-9.

55. Moghaddam AAS, Kargozar A, Zarei-Ghanavati M, et al. Screening for amblyopia risk factors in pre-verbal children using the Plusoptix photoscreener: a cross-sectional population-based study. $\mathrm{Br} J$ Ophthalmol 2012;96:83-6.

56. Silbert DI, Matta NS. Performance of the spot vision screener for the detection of amblyopia risk factors in children. $J$ AAPOS 2014;18:169-72.

57. Birch E, Williams C, Drover J, et al. Randot preschool stereoacuity test: normative data and validity. J AAPOS 2008;12:23-6.

58. Fawcett SL, Birch EE. Interobserver test-retest reliability of the randot preschool stereoacuity test. J AAPOS 2000;4:354-8.

59. Jost RM, Stager D, Dao L, et al. High specificity of the pediatric vision scanner in a private pediatric primary care setting. $J$ AAPOS 2015;19:521-5

60. Donahue SP, Arthur B, Neely DE, et al. Guidelines for automated preschool vision screening: a 10-year, evidence-based update. $J$ AAPOS 2013:17:4-8.

61. Pan Y, Tarczy-Hornoch K, Cotter SA, et al. The multi-ethnic pediatric eye disease study (MEPEDS) group. visual acuity norms in preschool children: the multi-ethnic pediatric eye disease study. Optom Vis Sci 2009;86:607-12.

62. Maguire MG, Vision in Preschoolers Study Group. Children unable to perform screening tests in vision in preschoolers study: proportion with ocular conditions and impact on measures of test accuracy. Invest Ophthalmol Vis Sci 2007;48:83-7.

63. Wang C, Bovaird S, Ford-Jones EL, et al. Vision and hearing screening in school settings: reducing barriers to children's achievement. Paediatr Child Health 2011;16:271-2.

64. Ying G-S, Kulp MT, Maguire M, et al. Sensitivity of screening tests for detecting vision in preschoolers-targeted vision disorders when specificity is 94\%. Optom Vis Sci 2005;82:432-8.

65. Harvey EM, Dobson V, Clifford-Donaldson CE, et al. Prevalence of astigmatism in native American infants and children. Optom Vis Sci 2010;87:400-5

66. Tarczy-Hornoch K, Varma R, Joint Writing Committee for the MultiEthnic Pediatric Eye Disease Study and the Baltimore Pediatric Eye Disease Study Groups. Risk factors for astigmatism in preschool children: the multi-ethnic pediatric eye disease and Baltimore pediatric eye disease studies. Ophthalmol 2011;118:197401981. 